\title{
Bon Cabai Sebagai Alternatif Produk Olahan Cabai dan Peningkatan Pendapatan Petani di Saat Pandemi Covid-19
}

\author{
Chili Powder as an Alternative of Processed Chili Products and Increasing Farmers' Income \\ during Covid-19 Pandemic
}

Heri Akhmadi*
Pujastuti Sulistyaning Dyah
Department of $\quad$ Agribusiness,
Universitas Muhammadiyah
Yogyakarta, Bantul, Special Region of
Yogyakarta, Indonesia

email: heriakhmadi@umy.ac.id
Kata Kunci
Kelompok Wanita Tani
Pandemi Covid-19
Pendapatan petani
Produk olahan cabai
Keywords:
Farmer Women's Group
Covid-19 pandemic
Farmers' income
Chili processed products
Received: December 2020
Pccepted: Mablished: June 2021

\begin{abstract}
Abstrak
Cabai merupakan tanaman yang banyak dibudidayakan oleh petani di Dusun Ngentak Desa Seloharjo Kecataman Pundong, Kabupaten Bantul, Daerah Istimewa Yogyakarta. Selama ini hasil cabai dijual dalam bentuk mentah atau dimasak untuk konsumsi keluarga. Harga cabai yang fluktuatif terutama saat musim panen dan diperparah oleh adanya pandemi Covid-19 telah membuat petani mengalami kerugian karena turun drastis dan alternatif produk olahannya yang terbatas. Kegiatan pengabdian masyarakat ini bertujuan untuk mencari alternatif produk olahan cabai untuk meningkatkan nilai tambah produk olahan dan sebagai alternatif peningkatan pendapatan petani di saat pandemi. Metode yang digunakan adalah survey, observasi dan pelatihan. Hasil dari kegiatan pengabdian masyarakat ini adalah pengembangan produk olahan cabai berbentuk bon cabai yang bisa menjadi alternatif produk olahan berbahan dasar cabai di saat harga cabai turun. Kegiatan ini melibatkan Kelompok Wanita Tani sekaligus dapat menghidupkan kegiatan kelompok. Melalui pengembangan produk bon cabai ini selain menjadi alternatif produk olahan cabai juga dapat menjadi bagian dari upaya peningkatan pendapatan petani terlebih di saat pandemi.
\end{abstract}

\begin{abstract}
Chili is a widely cultivated plant by farmers in the Ngentak sub-village, Seloharjo Village, Pundong District, Bantul Regency, Special Region of Yogyakarta. In general, chili is sold as a fresh product or utilized for daily consumption. However, chili price fluctuation, especially during the harvest season and exacerbated by the Covid-19 pandemic, sometimes causes farmers to experience losses since there is a limited alternative of chili processed products. This community service aims to find an alternative of chili processed products to increase the added value of chili and as an alternative to increasing farmers' income during a pandemic. The methods used are survey, observation, and training. The result of this community service program is the development of processed chili products in the form of chili powder which can be an alternative to processed chili-based products when the chili price falls. This activity involves the Women Farmers Group as well as enlivens the group activities. Besides being an alternative to processed chili products, the development of this chili powder product can also be part of increasing farmers' income, especially during a pandemic.
\end{abstract} (http://creativecommons.org/licenses/by-sa/4.0/). DOI: https://doi.org/10.33084/pengabdianmu.v6i4.1857

\section{PENDAHULUAN}

Desa dan pertanian merupakan dua hal yang tidak bisa dipisahkan. Selain secara geografis pertanian umumnya tumbuh dan berkembang di perdesaan (Arham et al.,
2019), mayoritas penduduk Indonesia juga tinggal di pedesaan dan dengan mata pencaharian sebagai petani (Badan Pusat Statistik, 2018). Oleh karena itu, pengembangan usahatani di desa menjadi hal yang penting dilakukan. 
Demikian halnya dengan kegiatan pertanian yang ada di Dusun Ngentak, salah satu dusun yang merupakan wilayah Desa Seloharjo, Kecamatan Pundong, Kabupaten Bantul, Daerah Istimewa Yogyakarta. Terletak di tepi aliran Sungai Opak membuat dusun ini mempunyai keunggulan geografis dengan lahan yang relatif subur dan kontur tanah yang cenderung landai atau datar (Pemerintah Desa Seloharjo, 2017). Didukung oleh ketersediaan air yang cukup dibanding dusun lain di Desa Seloharjo, membuat Dusun Ngentak mempunyai potensi yang baik untuk mengembangkan kegiatan pertanian.

Salah satu kegiatan usahatani yang banyak dikembangkan oleh warga dan petani di Dusun Ngentak adalah budidaya cabai. Ada berbagaijenis cabai yang diusahakan petani Dusun Ngentak, namun yang paling banyak ditanam adalah jenis cabai rawit. Cabai rawit banyak dibudidayakan selain karena jenis cabai yang banyak digunakan sebagai bumbu masakan (Zamrodah \& Pintakami, 2020), juga karena harga cabai rawit yang terkadang tinggi sehingga menarik petani untuk memilihnya sebagai pilihan yang ditanam.

Meskipun harga jual cabai rawit pada waktu tertentu sangat menjanjikan, namun usahatani cabai juga mempunyai banyak tantangan terutama saat musim pasokan cabai melimpah dan harga menjadi turun (Timisela et al., 2020). Permasalahan fluktuasi harga cabai juga ditemukan pada petani Dusun Ngentak menurut hasil observasi lapangan. Harga cabai bisa naik cukup tinggi terutama pada musim hujan dan lebaran (Van et al., 2017), namun pada saat yang lain turun sangat drastis. Misalnya pada musim tanam 2019/2020 fluktuasi harga cabai cukup tajam, dari harga tertinggi sekitar Rp.45.000,pada Bulan November-Desember 2019 menjadi sekitar Rp. 5.000,- saat musim panen. Selain itu, pada tahun 2020 adanya pandemi Covid-19juga menjadi salah satu sebab turunnya harga karena pasokan ke pasar luar daerah terganggu oleh pembatasan sosial (Singh et al., 2021). Permasalahan fluktuasi harga cabai memang tidak mungkin hanya diselesaikan oleh petani, karena itu merupakan permasalahan yang kompleks dan memerlukan andil banyak pihak untuk menyelesaikan (Anwarudin et al., 2015). Lain dari pada itu, hasil tanaman cabai yang selama ini dipanen oleh petani umumnya hanya dijual dalam bentuk mentah. Sehingga saat terjadi penurunan harga cabai petani tidak bisa banyak berbuat dengan hasil panenannya. Belum ada upaya untuk melakukan pengolahan cabai sebagai alternatif produk untuk menghadapi fluktuasi harga terutama saat harga jual menurun. Oleh karena itu perlu diupayakan bagaimana solusi untuk menghadapi fluktuasi harga cabai bagi petani Dusun Ngentak dan sekaligus dapat meningkatkan pendapatannya terlebih di saat pandemi.

\section{METODOLOGI}

Kegiatan pengabdian masyarakat ini dilaksanakan di Dusun Ngentak, Desa Seloharjo Kecamatan Pundong Kabupaten Bantul, Daerah Istimewa Yogyakarta. Dusun Ngentak dipilih sebagai lokasi pengabdian karena merupakan wilayah yang paling banyak petani membudidayakan cabai di Desa Seloharjo. Metode pelaksanaannya meliputi survey kondisi wilayah, observasi kegiatan, perencanaan program, penyuluhan dan pelatihan. Survey wilayah dilakukan untuk memahami keadaan geografis wilayah, potensi dan sumber daya alam Dusun Ngentak, Desa Seloharjo. Selain itu, survey juga dilakukan untuk mengetahui potensi sumber daya yang ada agar dapat dikembangkan dan diberdayakan dengan maksimal sehingga dapat meningkatkan ekonomi masyarakat.

Observasi kegiatan bertujuan untuk mengetahui kegiatan dan aktivitas sehari-hari masyarakat Dusun 
Ngentak, sehingga dapat menganalisis programprogram yang akan dijalankan yang dapat dimaksimalkan sesuai tujuan kegiatan pegabdian. Termasuk pada kegiatan ini adalah melakukan observasi kegiatan yang pernah dilakukan sebelumnya.

Setelah dilakukan survey wilayah dan observasi kegiatan, selanjutnya dilakukan perencanaan program kerja dengan melibatkan pemangku kepentingan di Dusun Ngentak, baik tokoh masyarakat maupun perwakilan warga. Kegiatan pelatihan yang dipilih adalah pengolahan cabai mencaji bon cabai. Pemilihan jenis olahan ini dengan alasan selain mempunyai nilai tambah secara ekonomi juga dapat mempunya daya tahan/simpan yang lebih lama. Alasan lainnya karena teknologi pembuatan bon cabai relatif mudah untuk dikerjakan oleh ibu-ibu wanita tani yang terlibat dalam kegiatan ini (Novita \& Rahmawati, 2020).

Adapun alat dan bahan yang digunakan dalam pelaksanaan kegiatan pelatihan pembuatan bon cabai terdiri dari beberapa yang semua tersedia di Dusun Ngentak. Peralatan yang digunakan antara lain: chooper, saringan stainless, loyang, baskom, oven, wajan dan kompor. Adapun bahan yang diperlukan adalah cabai rawit, cabai merah, ebi, bawang putih, garam dan penyedap rasa.

\section{HASIL DAN PEMBAHASAN}

Kegiatan pengabdian ini dilaksanakan melalui berbagai rangkaian kegiatan mulai dari kegiatan observasi wilayah, panyusunan program, sosialisasi, pelaksanaan kegiatan penyuluhan dan pelatihan. Berikut ini detail hasil dari masing-masing kegiatan:

\section{Observasi wilayah}

Dusun Ngentak secara administratif masuk dalam wilayah Desa Seloharjo, Kecamatan Pundong, Kabupaten Bantul, Daerah Istimewa Yogyakarta. Adapun secara geografis terletak pada kordinat
7,9782474 lintang selatan dan 110,3394609 bujur timur. Dusun Ngentak berbatasan dengan Dusun Krapiyak di sebelah utara, Dusun Kalipakem di sebelah selatan, Dusun Biro di sebelah barat, dan Dusun Karang Asem disebelah timur. Adapun jarak ke ibukota kabupaten sejauh $9 \mathrm{~km}$ dan ibukota propinsi (Titik 0 Kota Yogyakarta) sejauh $21,5 \mathrm{~km}$.

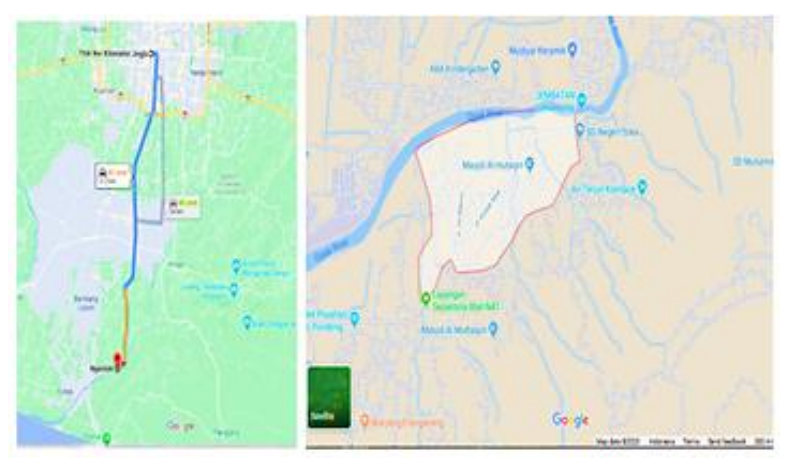

Gambar 1. Peta lokasi Dusun Ngentak

Luas wilayah Dusun Ngentak secara keseluruhan $593.790 \mathrm{~m}^{2}$. Adapun penggunaan lahan paling banyak adalah lahan pekarangan, selanjutnya lahan sawah dan untuk pemukiman. Detail penggunaan lahan di Dusun Ngentak adalah sebagai berikut.

1. Pekarangan : $414.490 \mathrm{~m}^{2}$

2. Persawahan : $127.256 \mathrm{~m}^{2}$

3. Pemukiman : $107.25 \mathrm{~m}^{2}$

Secara demografis, jumlah penduduk Dusun Ngentak pada tahun 2020 mencapai 678 jiwa yang terdiri dari 200 kepala keluarga, dengan rincian laki-laki sekitar $40 \%$ dan perempuan $60 \%$. Semua warga Dusun Ngentak beragama Islam (100\%) dengan latar belakang Pendidikan mayoritas lulusan sekolah menengah atas dan perguruan tinggi. Adapun dari sisi pekerjaan mayoritas petani $(40 \%)$ dan buruh $(30 \%)$, selanjutnya sekitar 20\% PNS dan 10\% swasta berdasarkan dari hasil wawancara terhadap Kepala Dusun Ngentak.

Berdasarkan aspek kelembagaan, Dusun Ngentak terdiri dari empat Rukun Tetanga (RT). Adapun kelembagaan organisasi masyarakat dan pemuda diantaranya 
Pimpinan Cabang Muhammadiyah Pundong, Dasa Wisma PKK, dan Karang Taruna Dusun Ngentak, Angkatan Remaja Masjid Ngentak (ARISTA), GAPOKTAN, Posyandu, PAUD Qurrata A'yyun, TPA dan TK ABA Nurhuda.

\section{Penyusunan program}

Setelah dilakukan observasi dan identifikasi potensi wilayah, selanjutnya dilakukan perencanaan dan penyusunan program. Kegiatan penyusunan program ini dilaksanakan dengan melibatkan segenap pemangku kepentingan, mulai dari tim pengabdian, Kepala Dusun, ibu-ibu anggota PKK dan warga.

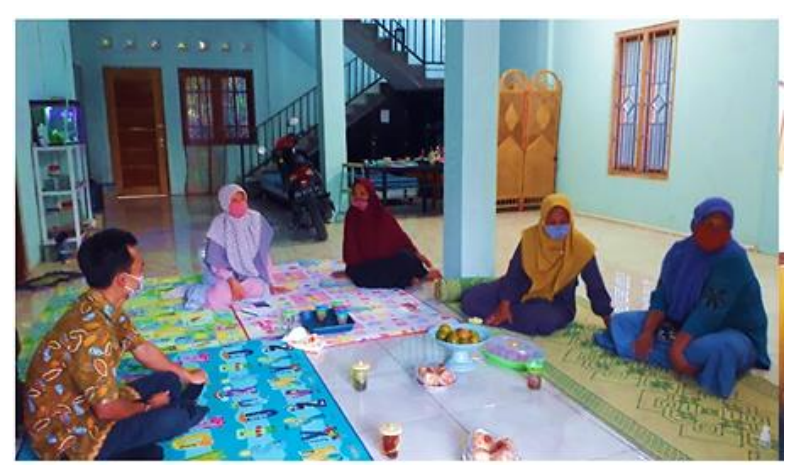

Gambar 2. Koordinasi penyusunan program

Berdasarkan diskusi dengan warga dan para pihak terkait. Ada beberapa hal yang menjadi keluhan dan permasalahan warga yang umumnya berprofesi sebagai petani. Salah satunya adalah permasalahan yang selalu dihadapi petani cabai saat musim panen dimana harga cabai sangat rendah. Fenomena musiman ini bukan sekali saja dihadapi oleh petani. Bahkan pada tahun 2017 juga pernah terjadi dimana harga cabai mencapai Rp. $3.000,-/ \mathrm{kg}$ di tingkat petani di Desa Seloharjo (Hadi, 2017). Pada tahun 2020 hal itu terjadi lagi dan diperparah dengan adanya Pandemi Covid-19 dimana saluran distribusi cabai terganggu karena pembatasan sosial menyebabkan cabai hasil panen tidak terserap pasar.

Sementara itu hasil panen cabai selama ini hanya dijual dalam bentuk mentah. Belum ada upaya untuk peningkatan nilai tambah cabai untuk diolah menjadi produk olahan cabai lainnya yang bisa menjadi alternatif produ di saat harga cabai rendah. Pengolahan cabai menjadi makanan olahan dapat menjadi alternatif produk dan meningkatkan pendapatan petani, terlebih di saat pandemi (Kurniati et al., 2019; Elizabeth, 2019).

Selain permasalahan fluktuasi harga cabai, hal lain yang ditemui dari observasi dan survey lapangan adalah belum adanya kelembagaan kelompok yang dapat mewadahi aktivitas warga, khususnya ibu rumah tangga dalam hal pertanian. Meskipun selama ini warga sudah sering melakukan kegiatan bersama, namun itu semua melalui pertemuan kegiatan pengajian yang tidak terorganisasi khusus untuk pengembangan usahatani. Ibu rumah tangga bisa menjadi pendukung ekonomi keluarga (Qamariah \& Handayani, 2020).

Berdasarkan hasil observasi, dirumuskan ada dua program utama yaitu pelatihan pembuatan bon cabai sebagai alternatif olahan cabai dan pembentukan kelembagaan wanita tani. Program pertama dilakukan dengan tujuan agar warga mempunyai keterampilan dalam membuat produk alternatif olahan cabai sekaligus sebagai berpotensi untuk meningkatkan pendapatan keluarga terlebih di saat pandemi. Adapun program kedua ditujukan untuk memperkuat kelembagaan dan organisasi yang mendukung program pertama.

\section{Pelaksanaan program}

Sebagaimana hasil observasi, ada dua program dalam kegiatan pengabdian masyarakat di Dusun Ngentak yaitu pelatihan pembuatan bon cabai dan pembentukan kelembagaan kelompok wanita tani (KWT). Berikut ini detail pelaksanaan kedua program tersebut:

1. Pelatihan Pembuatan Bon Cabai

Kegiatan pelatihan pembuatan bon cabai dilaksanakan pada tanggal 11 Agustus 2020 bertempat di rumah salah satu warga. Pada awalnya kegiatan ini direncanakan dilaksanakan pada Bulan Maret 2020, namun karena adanya pandemi Covid- 
19 dan masih adanya larangan mengumpulkan orang akhirnya baru terlaksana pada Bulan Agustus 2020 dengan tetap menerapkan protokol kesehatan dalam pencegahan Covid-19. Pelatihan ini didahului dengan penyuluhan dan penjelasan teknis pembuatan bon cabai oleh Ir. Pujastuti Sulistyaning Dyah, M.M. Termasuk dalam hal ini penyiapan alat dan bahan untuk pembuatan bon cabai.

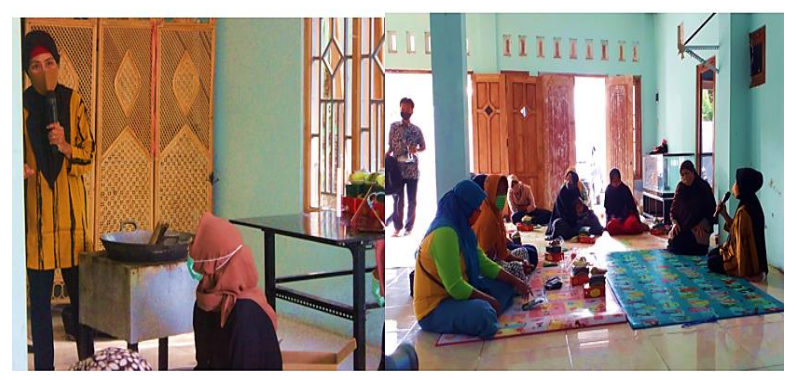

Gambar 3. Pelatihan pembuatan Bon Cabai

Peralatan yang digunakan pada pembuatan bon cabai adalah oven yang digunakan untuk mengeringkan cabai. Penggunaan oven ini sifatnya pilihan, karena bisa dikeringkan dengan menjemur. Bahkan menurut praktek yang dilakukan tim pengabdian, pengeringan menggunakan sinar matahari relatif lebih mudah dan merata dibandingkan dengan menggunakan oven. Dengan catatan cukup tersedia panas matahari (tidak mendung atau hujan). Alat selanjutnya adalah chooper untuk menghaluskan cabai, saringan stainless, loyang, baskom, wajan dan kompor. Bahan yang diperlukan adalah cabai rawit, cabai merah, ebi, bawang putih, garam dan penyedap rasa. Sedangkan mengenai tahapan pembuatan bon cabai meliputi:

a. Pengeringan Cabai

Langkah pertama dalam proses pembuatan bon cabai adalah dengan mengeringkan cabai rawit dan cabai merah/keriting yang akan digunakan untuk menghilangkan kadar airnya. Pengeringan bisa menggunakan oven atau dikeringkan dengan sinar matahari. Pada pangeringan dengan sinar matahari, tidak ada aturan baku berapa lama waktu untuk mengeringkan, karena tergantung lama sinar matahari dan juga kadar air dari cabai yang digunakan. Meskipun demikian ada yang menyarankan antara 4-5 hari (Malik et al., 2019).

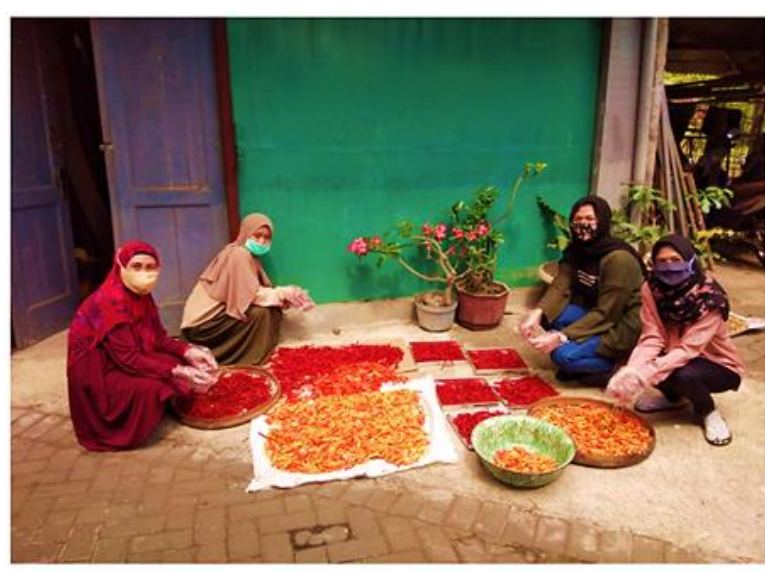

Gambar 4. Pengeringan cabai

b. Penghalusan Cabai

Tahap berikutnya adalah menghaluskan cabaicabai yang sudah dikeringkan menggunakan chooper atau blender sampai benar-benar halus. Setelah halus kemudian disaring menggunakan saringan sampai tidak ada cabai yang kasar.

c. Penambahan Bumbu

Langkah selanjutnya adalah penambahan bumbu untuk memberikan rasa. Bumbu-bumbu yang diperlukan cukup sederhana yaitu bawang putih, garam, ebi dan penyedap rasa. Bawang putihnya dipotong kecil-kecil kemudian digoreng setelah itu di blender sampai halus. Untuk ebinya sendiri di goreng juga hingga kecoklatan kemudian di blender sampai halus.

Setelah semua diblender dan dipisahkan, masukkan kembali ke bubuk cabai yang sudah disaring tadi dengan dicampur bawang putih, ebi, yang sudah di blender. Kemudian tambahkan garam, kaldu jamur dan penyedap 
rasa. Setelah itu campur hingga rata, bisa diaduk atau diblender ulang agar tercampur rata. Sebelum dikemas bubuk cabai digonso sebentar saja agar bubuk bon cabai matang dan didiamkan hingga dingin sebelum dikemas.

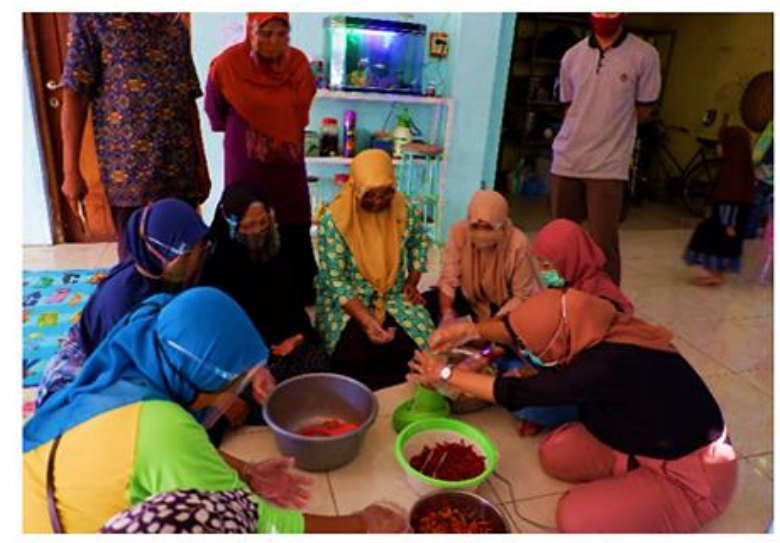

Gambar 5. Penghalusan cabai

\section{d. Pengemasan}

Pengemasan adalah tahap terakhir dari proses produkdi bon cabai. Meskipun ini merupakan hal yang terakhir, namun juga merupakan tahapan yang penting. Fungsi utama dari kemasan sendiri adalah untuk melindungi, menyimpan, memudahkan distribusi, promosi dan layanan garansi (Ketelsen et al., 2020). Oleh karena itu perlu penanganan yang hati-hati agar kualitas produk terjaga dan tahan lama.

Setelah berhasil membuat produk bon cabai, selanjutnya dilakukan tes pasar untuk mengetahui potensi pasar produk Bon Cabai KWT Ngentak. Pada tahap awal, produk Bon Cabai KWT Ngentak ini dipasarkan di Pasar Tani Gabusan, Bantul, dengan harga per kemasan Rp. 9.000,- untuk ukuran $50 \mathrm{~g}$.

Sebagai catatan, untuk setiap $15 \mathrm{~kg}$ bahan baku cabai, dapat dihasilkan sekitar 30 botol bon cabai kemasan $50 \mathrm{~g}$ atau dengan kata lain tiap $1 \mathrm{~kg}$ bahan cabai dapat dihasilkan $100 \mathrm{~g}$ bon cabai. Dengan harga per kemasan Rp. 9.000/kg cabai dapat dihasilkan bon cabai dengan harga jual Rp. 18.000,- belum dipotong biaya produksi dan lainlain. Hal ini tentu bisa menjadi alternatif produk olahan, mengingat pada saat tertentu harga cabai bisa jatuh pada kisaran harga Rp. 3.000,-/kg.

Langkah selanjutnya untuk mendukung pengembangan produk adalah perlunya diupayakan kegiatan pemasaran yang baik sehingga produk dapat diterima oleh konsumen. Pengembangan pemasaran produk perlu mempertimbangkan penggunaan teknologi informasi dan komunikasi agar informasi produk lebih cepat dan murah. Salah satu yang paling mudah dengan mengoptimalkan penggunaan telepon pintar (smartphone) yang banyak digunakan oleh ibu-ibu anggota KWT. Smartphone merupakan perangkat elektronik yang dapat dengan mudah digunakan dalam pemasaran produk (Akhmadi \& Fauzan, 2020).

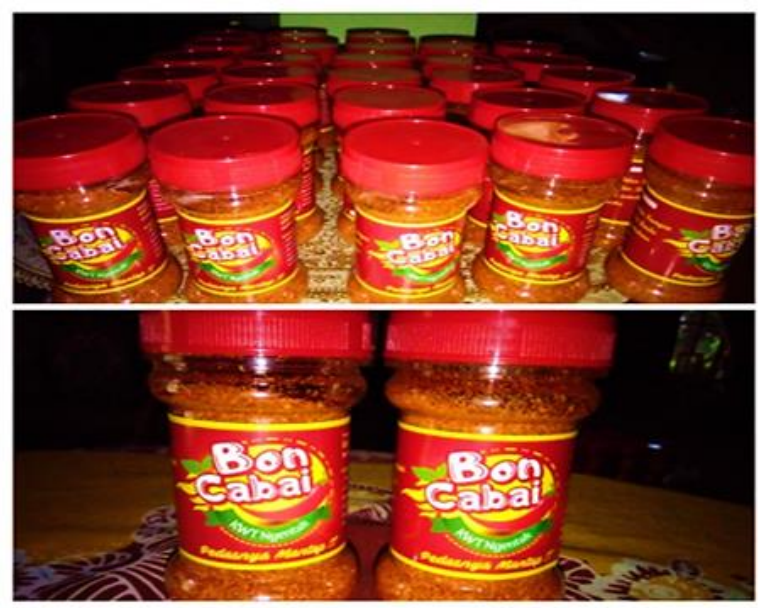

Gambar 6. Kemasan Bon Cabai Ngentak

2. Pembentukan Kelompok Wanita Tani Kelembagaan petani atau dalam hal ini para perempuan istri petani merupakan sesuatu yang penting tidak hanya dalam pengorganisasian kegiatan tetapi juga dalam upaya peningkatan ekonomi dan keberlanjutan usaha (Aprillia \& Barlan, 2020). Oleh karena itu, pada kegiatan pengabdian ini 
selain peningkatan pengentahuan dan keterampilan tentang pengolahan cabai, juga dilakukan pelembagaan kelompok ibu-ibu para istri petani dalam wadah KWT. Kegiatan ini didahului dengan penyuluhan tentang pentingnya organisasi kelompok wanita tani yang disampaikan oleh Heri Akhmadi, S.P., M.A.

Pada dasarnya ibu-ibu para istri petani di Dusun Ngentak selama ini sudah terbiasa melakukan kegiatan bersama, namun belum ada wadah resmi organisasi yang memayungi. Untuk itu setelah dimusyarahkan bersama akhirnya disepakati dibentuk KWT Ngentak.

Sebagai langkah awal dalam pengorganisasian KWT, disepakati dipilih beberapa pengurus dan susunan organisasinya. Struktur organisasi terdiri dari Ketua, Sekretaris dan Bendahara. Selanjutnya sebagai upaya untuk memotivasi dalam berorganisasi, pada kegiatan ini juga diserahkan bantuan uang pembinaan, seperangkat alat tulis kantor dan peralatan rumah tangga untuk mendukung kegiatan KWT Ngentak berikutnya.

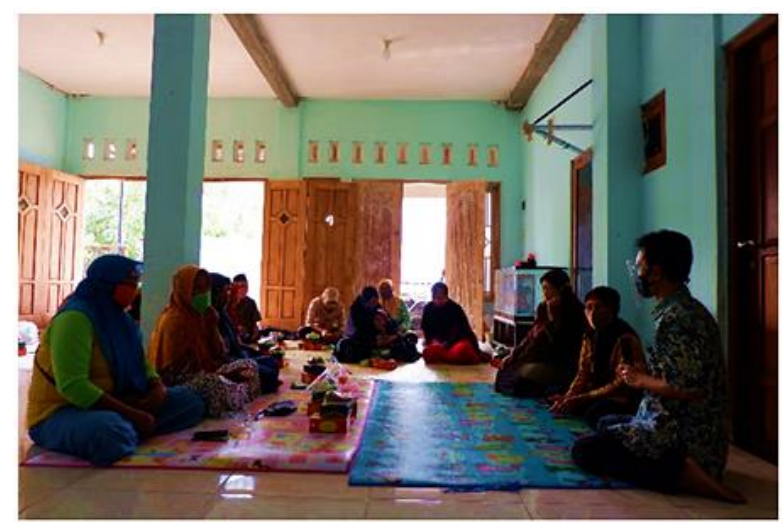

Gambar 7. Penyuluhan urgensi KWT

Setelah terbentuknya kelembagaan "KWT Ngentak" diharapkan gerak organisasi wanita tani di Dusun Ngentak dapat berkelanjutan, utamanya dalam mendukung ekonomi rumah tangga petani. Hasil penelitian menunjukkan bahwa keberadaan
Kelompok Wanita Tani dapat meningkatkan nilai tambah produk pertanian, meningkatkan pendapatan keluarga dan ekonomi desa (Evendi \& Suryadharma, 2020).

3. Monitoring dan Evaluasi

Kegiatan monitoring dan evaluasi merupakan tahapan akhir dari rangkaian kegitan pengabdian masyarakat di Dusun Ngentak. Tujuan kegiatan ini selain untuk mengetahui sejauh mana pemahaman peserta terhadap materi pelatihan (Onsardi et al., 2019), juga untuk memantau sejauh mana kegiatan ini dapat mencapai rencana yang sudah disusun sebelumnya. Monitoring dilakukan beberapa kali baik langsung ke lokasi maupun secara daring mengingat kondisi masih pandemi.

Hasil monitoring dan evaluasi menunjukkan bahwa dalam aspek pengetahuan tentang alternatif produk olahan cabai, anggota kelompok wanita tani sudah bisa memahami materi yang diberikan. Para petani juga sudah mencoba beberapa alternatif baik metode pengolahan bon cabai maupun dalam pengemasan produknya berdasarkan pengalaman mereka.

Namun demikian, dalam aspek peningkatan peningkatan pendapatan petani masih belum terlalu dirasakan oleh anggota KWT. Volume produksi yang masih terbatas, margin keuntungan yang relatif kecil membuat penerimaan hasil penjualan juga kecil meskipun secara ekonomi sudah menguntungkan. Salah satu upaya untuk dapat meningkatkan keuntungan adalah dengan meningkatkan efisiensi dalam proses produksi (Fauzan \& Akhmadi, 2017). Hal ini menjadi tantangan bagi semua pihak untuk bisa meningkatkannya di masa depan.

\section{KESIMPULAN}

Berdasarkan hasil kegiatan pengabdian masyarakat yang dilakukan di Dusun Ngentak, disimpulkan bahwa 
Bon cabai dapat menjadi alternatif produk olahan cabai yang mempunyai nilai tambah secara ekonomi bagi petani anggota Kelompok Wanita Tani di Dusun Ngentak terutama di saat harga cabai tidak layak secara ekonomi terlebih saat pandemi. Adapun tindak lanjut kegiatan yang perlu dilakukan untuk mendukung keberlanjutan usaha pengolahan cabai adalah perbaikan proses produksi dengan membuat panduan produksi, perbaikan kemasan dan pengembangan pemasaran produk. Selain itu juga perlu diupayakan legalitas produk meliputi pengurusan PIRT dan sertifikat halal.

\section{UCAPAN TERIMA KASIH}

Penulis mengucapkan terima kasih kepada LP3M Universitas Muhammadiyah Yogyakarta atas Hibah Pengabdian Masyarakat Batch 3 tahun 2019/2020. Ucapan terima kasih juga terhadap Pemerintah Desa Seloharjo, Kecamatan Pundong, khususnya Kepala Dusun Ngentak pengurus dan anggota KWT Ngentak serta segenap mahasiswa program studi Agribisnis UMY yang telah membantu pelaksanaan kegiatan pengabdian ini.

\section{REFERENSI}

Akhmadi, H., Fauzan, M. 2020. Smartphone Adoption on Fruit Marketing Communication: a Traders Perception. Jurnal Agrisep: Kajian Masalah Sosial Ekonomi Pertanian dan Agribisnis. 19(2):433-446. https://doi.org/10.31186/agrisep.19.2.433446

Anwarudin, M.J., Sayekti, A.L., Marendra, A.K., Hilman, Y. 2015. Dinamika Produksi Dan Volatilitas Harga Cabai: Antisipasi Strategi Dan Kebijakan Pengembangan. Pengembangan Inovasi Pertanian. 8(1):33-42. http://dx.doi.org/10.21082/pip.v8n1.2015.33 $-42$

Aprillia, R., Barlan, Z.A. 2020. Hubungan antara Dinamika Kelompok dengan Keberlanjutan Kelembagaan. Jurnal Sains Komunikasi dan
Pengembangan Masyarakat. 4(1):99-112. https://doi.org/10.29244/jskpm.4.1.99-112

Arham, I., Sjaf, S., Darusman, D. 2019. Strategi Pembangunan Pertanian Berkelanjutan di Pedesaan Berbasis Citra Drone (Studi Kasus Desa Sukadamai Kabupaten Bogor). Jurnal Ilmu Lingkungan. 17(2):245-255. https://doi.org/10.14710/jil.17.2.245-255

Badan Pusat Statistik. 2018. Penduduk 15 Tahun Ke Atas yang Bekerja menurut Lapangan Pekerjaan Utama 1986-2021.

https://www.bps.go.id/statictable/2009/04 /16/970/penduduk-15-tahun-ke-atas-yangbekerja-menurut-lapangan-pekerjaan-utama1986-2018.html

Elizabeth, R. 2019. Pengembangan Agribisnis Dan Pengolahan Mendukung Pensejahteraan Petani Cabe Merah. Mimbar Agribisnis: Jurnal Pemikiran Masyarakat Ilmiah Berwawasan Agribisnis. 5(2):413-435. http://dx.doi.org/10.25157/ma.v5i2.2413

Evendi, A.A., Suryadharma, P. 2020. Peran Kelompok Wanita Tani Dalam Perekonomian Masyarakat Desa Neglasari Kabupaten Bogor. Jurnal Pusat Inovasi Masyarakat. 2(2):252-256.

Fauzan, M., Akhmadi, H. 2017. Income Analysis and Household Welfare Level of Dairy Farmer In Pagerjurang Permanent Settlement After the 2010 Eruption of Mount Merapi, Yogyakarta Indonesia. In Proceeding of $3^{\text {rd }}$ International Conference on Food, Agriculture and Natural Resources 2017. Selangor, Universiti Putra Malaysia.

Hadi, U. 2017. Ini Alasan Petani di Bantul Gratiskan Cabai Rawitnya. https://news.detik.com/beritajawa-tengah/d-3646520/ini-alasan-petani-dibantul-gratiskan-cabai-rawitnya

Ketelsen, M., Janssen, M., Hamm, U. 2020. Consumers' response to environmentally-friendly food packaging - A systematic review. Journal of Cleaner Production. 254:120123. https://doi.org/10.1016/j.jclepro.2020.120123

Kurniati, N., Jafrizal, J., Mufriantie, F. 2019. Teknologi Pengolahan Cabe Merah Bagi Kelompok Wanita Tani Desa Sukasari Kabupaten Kepahiang. JAPI (Jurnal Akses Pengabdian Indonesia). 4(1):12-17. https://doi.org/10.33366/japi.v4i1.1215 
Malik, A.R., Cahyani, I., Maisarani, S., Rozi, T. 2019. Pengembangan Potensi Desa Penedagandor Melalui Pengolahan Manisan Tomat Dan Bon Cabai. Jurnal Warta Desa (JWD). 1(1):34-41. https://doi.org/10.29303/jwd.v1i1.26

Novita, D.D., Rahmawati, W. 2020. Pemberdayaan Wanita Tani Dalam Usaha Produksi Abuca (Abon Dan Bubuk Cabai) Di Kecamatan Adiluwih Kabupaten Pringsewu. Jurnal Pengabdian Kepada Masyarakat Sakai Sambayan. 4(2):105-109.

http://dx.doi.org/10.23960/jss.v4i2.169

Onsardi, O., Wati, D., Anjani, R. 2019. Tata Kelola Adminitrasi Keuangan, Dan Pembangunan Desa Tepi Laut Kabupaten Bengkulu Utara. Jurnal Pengabdian Masyarakat Bumi Rafflesia. 2(2):169-176.

https://doi.org/10.36085/jpmbr.v2i2.445

Pemerintah Desa Seloharjo. 2017. Gambaran Umum Kondisi Desa Seloharjo. Bantul: Pemerintah Desa Seloharjo.

https://seloharjo.bantulkab.go.id/first

Qamariah, N., Handayani, R. 2020. Pemberdayaan Para Ibu Rumah Tangga di Kawasan Wisata Flamboyan Kota Palangka Raya Kalimantan Tengah sebagai Upaya Peningkatan Derajat Kesehatan dan Ekonomi Masyarakat. PengabdianMu: Jurnal Ilmiah Pengabdian kepada Masyarakat. 5(3):254-263. https://doi.org/10.33084/pengabdianmu.v5i 3.1431

Singh, S., Kumar, R., Panchal, R., Tiwari, M.K. 2021. Impact of COVID-19 on logistics systems and disruptions in food supply chain. International Journal of Production Research. 59(7):1993-2008. https://doi.org/10.1080/00207543.2020.17920 00

Timisela, N.R., Salampessy, Y.E., Apituley, Y.M.T.N. 2020. Analisis Pembentukan Harga Komoditas Cabai Rawit dan Bawang Merah Pada Tingkat Eceran di Kota Ambon. Jurnal Budidaya Pertanian. 16(1):31-41. https://doi.org/10.30598/jbdp.2020.16.1.31

Van, J.C., Huang, W.C., Anindita, R., Chang, W.I., Yang, S.H. 2017. Price Volatility of Cayenne Pepper and Red Chili Pepper in Papua and Maluku Provinces, Indonesia. Scholars Journal of Economics, Business and Management. 4(9):590-
599.

https://doi.org/10.21276/sjebm.2017.4.9.2

Zamrodah, Y., Pintakami, L.B. 2020. Pendapatan dan kelayakan usahatani cabai rawit. Journal of Agricultural Socio-Economics (JASE). 1(1):48-53. https://doi.org/10.33474/jase.v1i1.7242 